Journal of Current and Advance Medical Research

January 2020, Vol. 7, No. 1, pp.12-16

http://www.banglajol.info/index.php/JCAMR

ISSN (Print) 2313-447X

ISSN (Online) 2413-323X

NLM Catalog ID 101673828

DOI: https://doi.org/10.3329/jcamr.v7i1.46424

ORIGINAL ARTICLE marom

\title{
Surgical Management and Per-operative Findings of Women with Ectopic Pregnancy
}

\author{
Naheed Fatema ${ }^{1}$, Zannatul Ferdosh ${ }^{2}$, Sherajum Munira ${ }^{3}$, KAM Mahbub Hasan ${ }^{4}$, Nasim Iftekhar \\ Mahmud $^{5}$, Shahla Khatun ${ }^{6}$
}

${ }^{1}$ Resident Surgeon, Department of Obstetrics and Gynecology, Bangladesh Medical College Hospital, Dhaka, Bangladesh; ${ }^{2}$ Medical Officer, District Sadar Hospital, Lakshmipur, Bangladesh; ${ }^{3}$ Assistant Registrar, Department of Obstetrics and Gynecology, Kurmitola General Hospital, Dhaka, Bangladesh; ${ }^{4}$ Medical Officer, Department of Cardiology, National Institute of Cardiovascular Diseases, Dhaka, Bangladesh; ${ }^{5}$ Junior Consultant, Anesthesiology, District Sadar Hospital, Lakshmipur, Bangladesh; ${ }^{6}$ National Professor \& Chairman, Green Life Medical College Hospital, Dhaka, Bangladesh

[Received on: 2 October 2019; Accepted on: 1 December 2019; Published on: 1 January 2020]

\section{Abstract}

Background: Management of ectopic pregnancy is very crucial issue for the survival of the patients. Objective: The purpose of the present study was to observe the surgical management and per-operative findings of women with ectopic pregnancy. Methodology: This cross-sectional study was carried out in the inpatient Department of Obstetrics and Gynaecology at Bangladesh Medical College Hospital, Dhaka, Bangladesh from January 2009 to December 2009 for a period of one (1) year. All clinically suspected cases of ectopic pregnancy within the reproductive age admitted in the department of Obstetrics and Gynaecology at the Bangladesh Medical College Hospital, Dhaka were included in the present study. In most of the cases, laparoscopy or laparotomy was done to confirm the diagnosis and manage the cases. Result: A total number of 48 cases of ectopic pregnancy women were recruited for this study. The highest number of ectopic pregnancy occurs in the ampulla of the fallopian tube which was 27(58.3\%) cases. The right tube had been found to be affected more than the left which was 30(62.5\%) cases and 18(37.5\%) cases respectively. Most of the patients were presented with ruptured tubal pregnancy which was $30(62.5 \%)$ cases. Opposite tube was normal looking in $25(52.1 \%)$ cases. Unilateral salpingectomy and salpingectomy with contra lateral tubectomy were operated in $32(66.7 \%)$ cases and $10(20.8 \%)$ cases respectively. Conclusion: In conclusion most of the ectopic pregnancy is occurred in the site of ampulla of fallopian tube in right side which are mostly surgically managed by unilateral salpingectomy. [Journal of Current and Advance Medical Research, January 2020;7(1):12-16]

Keywords: Surgical management; per-operative findings; ectopic pregnancy

Correspondence: Dr. Naheed Fatema, Resident Surgeon, Department of Obstetrics and Gynecology, Bangladesh Medical College Hospital, Dhanmondi, Dhaka, Bangladesh; Email: dr.naheedkoly@ gmail.com; Cell no.: +8801715301006

Cite this article as: Fatema N, Ferdosh Z, Munira S, Hasan KAMM, Mahmud NI, Khatun S. Surgical Management and Peroperative Findings of Women with Ectopic Pregnancy. J Curr Adv Med Res 2020;7(1):12-16

Funding: This study has been performed without any funding from outside else.

Conflict of Interest: There was no conflict of interest to any of the authors.

Contributions to authors: Fatema N, Ferdosh Z, Munira S involved in protocol preparation, data collection; statistical analysis Fatema N. Hasan KAMM, Mahmud NI, Khatun S had involved in manuscript writing \& revision of the manuscript.

Copyright: ( 2020 . Fatema et al. Published by Journal of Current and Advance Medical Research. This article is published under the Creative Commons CC BY-NC License (https://creativecommons.org/licenses/by-nc/4.0/). This license permits use, distribution and reproduction in any medium, provided the original work is properly cited, and is not used for commercial purposes. 


\section{Introduction}

Surgery still remains the treatment of choice of ectopic pregnancy in most of the cases particularly in the developing countries ${ }^{1}$. Surgery can be open or laparoscopic methods. Before deciding the final surgical treatment of the affected tube, the opposite tube and ovary should be examined and the procedure should be then taken account of the patient's age and future reproductive capacity as well as the nature of lesion ${ }^{2}$. Laparotomy followed by salpingectomy of the affected side has been a standard modality of treatment of ruptured ectopic pregnancy for many years ${ }^{3}$. Now a day conservative surgery with the preservation of the fallopian tube like linear salpingostomy, linear salpingotomy, segmental resection and end to end anastomosis may be indicated in haemodynamically stable patient with an unruptured tubal ectopic pregnancy who wishes to preserve fertility ${ }^{4}$.

Laparotomy is called for as soon as the diagnosis of ruptured ectopic pregnancy is made and the patient is in hospital ${ }^{5}$. In stable patients, laparoscopy is preferred over laparotomy because of the associated reduction in morbidity and cost ${ }^{4}$. Blood transfusion may be required before, during and after operation but operation must not be deferred until the woman is in good condition. Resuscitation and operation at the same time can be lifesaving. Immediate laparotomy and clamping of the bleeding vessels may be the only means of saving life of moribund patient ${ }^{6}$.

Laparoscopic treatment of tubal pregnancy offers numerous advantages reducing operating time, hospital stay and improves cosmetic result ${ }^{7}$. Though there are few numbers of studies on Ectopic pregnancy in Bangladesh, findings from international studies and clinical research show that greater awareness of risk factors and improved diagnostic technology allow ectopic pregnancy to be identified before development of life threatening events and can reduce other associated complications ${ }^{8}$.

Laparoscopic management should be the first line of treatment, if possible. Laparoscopic surgery is usually performed when the patient is haemodynamically stable and the beta hCG is more than $6000 \mathrm{IU} / \mathrm{L}^{9}$. The history is suggestive of minimal pelvic adhesions and when the pregnancy is confined within the tube. This procedure is, however mostly dependent on experience and expertise of the surgeon and the equipment facilities available ${ }^{10}$. This present study was undertaken to observe the surgical management and per-operative findings of women with ectopic pregnancy.

\section{Methodology}

This descriptive cross-sectional study was carried out in the inpatient Department of Obstetrics and Gynaecology at Bangladesh Medical College Hospital, Dhaka, Bangladesh from January 2009 to December 2009 for a period of one (1) year. All clinically suspected cases of ectopic pregnancy within the reproductive age admitted in the department of Obstetrics and Gynaecology at the Bangladesh Medical College Hospital during the study period were included in the present study. All clinically suspected cases of ectopic pregnancy, patients at 15 to 45 years of age were included in this study. Patients other than ectopic pregnancy were excluded from this study. Sample size was calculated by using appropriate formula. The sampling technique was consecutive sampling technique and this purposive sampling technique was used as per inclusions and exclusion criteria. After taking detailed history with particular scrutinization of the menstrual, obstetric and contraceptive history, a thorough physical examination was performed, and ectopic pregnancy was diagnosed clinically in a large number of cases. In some cases, investigations like pregnancy test, beta-hCG hormone and ultrasonography were done to support the clinical diagnosis. Hemoglobin estimation and blood grouping was done in all cases. Finally in most of the cases, laparoscopy or laparotomy was done to confirm the diagnosis and manage the cases. Histopathological confirmation was done in most of the cases. Data collection was conducted by researcher herself. All data were compiled and edited meticulously by thorough checking and rechecking. All omissions and inconsistencies were corrected and were removed methodically. All data were recorded systematically in preformed data collection form (questionnaire) and quantitative data was expressed as mean and standard deviation and qualitative data was expressed as frequency distribution and percentage. Statistical analysis was performed by using SPSS for windows version 12.0. 95\% confidence limit was taken. Probability value $<0.05$ was considered as level of significance. Prior to the commencement of this study, the research protocol were approved by the ethical committee (Local Ethical committee) of the Bangladesh Medical College Hospital, Dhaka. Informed consent was taken from the respondents prior to interview.

\section{Result}

The distribution of ${ }^{-}$ectopic pregnancy cases 
according to sites of ectopic gestation was recorded. In this study the highest number of ectopic pregnancy occurs in the ampulla of the fallopian tube which was $27(58.3 \%)$ cases followed by isthmus and fimbrial part which were $14(27.8 \%)$ cases and $6(11.1 \%)$ cases respectively. However, only $1(2.8 \%)$ case was in the interstitial part (Table 1).

Table 1: Distribution of Study Population According To Sites of Ectopic Gestation

\begin{tabular}{|l|c|c|}
\hline $\begin{array}{l}\text { Ectopic Gestation } \\
\text { Site }\end{array}$ & Frequency & Percent \\
\hline Ampulla & 27 & 58.3 \\
\hline Isthmus & 14 & 27.8 \\
\hline Fimbrial & 6 & 11.1 \\
\hline Interstitial part & 1 & 2.8 \\
\hline Total & $\mathbf{4 8}$ & $\mathbf{1 0 0 . 0}$ \\
\hline
\end{tabular}

The distribution of ectopic pregnancy cases according to the affected tubes were recorded. In this study right tube had been found to be affected more than the left which was 30(62.5\%) cases and $18(37.5 \%)$ cases respectively (Table 2 ).

Table 2: Ectopic Pregnancy Cases According to the Affected Tubes

\begin{tabular}{|l|c|c|}
\hline Affected Tubes & Frequency & Percent \\
\hline Right tube & 30 & 62.5 \\
\hline Left tube & 18 & 37.5 \\
\hline Total & $\mathbf{4 8}$ & $\mathbf{1 0 0 . 0}$ \\
\hline
\end{tabular}

The distribution of ectopic pregnancy cases according to tubal stats was recorded. Most of the patients were presented with ruptured tubal pregnancy which was $30(62.5 \%)$ cases and only $6(12.5 \%)$ cases were found un-ruptured. However, $12(25.0 \%)$ cases were diagnosed as to be tubal abortion (Table 3 ).

Table 3: Ectopic Pregnancy Cases According To Tubal Status

\begin{tabular}{|l|c|c|}
\hline Status & Frequency & Percent \\
\hline Ruptured & 30 & 62.5 \\
\hline Abortion & 12 & 25.0 \\
\hline Un-ruptured & 6 & 12.5 \\
\hline Total & $\mathbf{4 8}$ & $\mathbf{1 0 0 . 0}$ \\
\hline
\end{tabular}

Opposite tube was normal looking in $25(52.1 \%)$ cases, whereas the tube was pathological in the rest of 23(47.9\%) case. However, inflamed, peritubal adhesions and hydrosalpinx were found in $12(25.0 \%)$ cases, $6(12.5 \%)$ cases and $4(8.3 \%)$ cases respectively. Tubercles on the tube or pelvic was found in only $1(2.1 \%)$ case (Table 4$)$.

Table 4: Distribution of Ectopic Pregnancy Cases According To the Conditions of Opposite Tube

\begin{tabular}{|l|c|c|}
\hline Condition & Frequency & Percent \\
\hline Normal looking & 25 & 52.1 \\
\hline Inflamed & 12 & 25.0 \\
\hline Peritubal adhesions & 6 & 12.5 \\
\hline Hydrosalpinx & 4 & 8.3 \\
\hline $\begin{array}{l}\text { Tubercles on the } \\
\text { tube or pelvic }\end{array}$ & 1 & 2.1 \\
\hline Total & $\mathbf{4 8}$ & $\mathbf{1 0 0 . 0}$ \\
\hline
\end{tabular}

The distribution of ectopic pregnancy cases was observed according to management. Salpingectomy with or without contra-lateral tubectomy was the most common operation done which was 42(87.5\%). Within this unilateral Salpingectomy and Salpingectomy with contra lateral tubectomy were operated in $32(66.7 \%$ ) cases and $10(20.8 \%)$ cases respectively. Only in 6(12.5\%) cases linear salpingostomy were performed (Table 5).

Table 5: Distribution of Ectopic Pregnancy Cases According to Management

\begin{tabular}{|l|c|c|}
\hline Types of Operation & Frequency & Percent \\
\hline $\begin{array}{l}\text { Unilateral } \\
\text { Salpingectomy }\end{array}$ & 32 & 66.7 \\
\hline $\begin{array}{l}\text { Salpingectomy with } \\
\text { contra lateral tubectomy }\end{array}$ & 10 & 20.8 \\
\hline Linear Salpingostomy & 6 & 12.5 \\
\hline Total & $\mathbf{4 8}$ & $\mathbf{1 0 0 . 0}$ \\
\hline
\end{tabular}

\section{Discussion}

Whenever tubal pregnancy is diagnosed or suspected the patient should be admitted to hospital immediately, provided that she is not in a state of shock. It is preferable that shock must be treated immediately before she is moved.

Among all of the patients laparotomy has been done with resuscitative measures if has been needed and per operative findings are evaluated. At the time of operation, tubal ectopic pregnancy is found to be more on right side tube $(61.0 \%)$ than the left tube $(39.0 \%)$. Most of the patients $(81.0 \%)$ have ruptured tubal pregnancy. Only in $8.0 \%$ cases tubes 
are distended and unruptured; however, $11.0 \%$ cases are diagnosed to be tubal abortion. There are $58.0 \%$ cases ampullary; $28.0 \%$ cases are isthmic; $11.0 \%$ cases are fimbrial and $3.0 \%$ cases are interstitial location. Almost Similar observation has been made by Kulsum ${ }^{11}$ and Zabin $^{12}$ in two local studies. Archibong et $\mathrm{al}^{13}$ has found common site of implantation in ampulla $80.0 \%$ followed by isthmus $(11.0 \%)$, fimbria (4.0\%), cornu $(2.0 \%)$ and interstitial $(3.0 \%)$. Right tube has been found to be affected more in many reports. In this country ectopic tubal pregnancy has been found ruptured in many of the cases. This may be due to the fact that the study patients have come to the hospital at a later stage and the adequate facilities are not available to diagnose the case at an early stage.

The other sided tube are examined and has been found in $58.0 \%$ cases normal looking. In all other cases tubes are found clinically pathological like inflamed, adhesions and hydrosalpinx. Almost similar observation has been made by Kulsum ${ }^{11}$. There are $3.0 \%$ cases where tubercles are found on the tubes and in the pelvis. These cases are later confirmed histopathologically as tuberculosis. In this study there are no mortality from ectopic pregnancy during the study period.

During laparotomy the appropriate surgery for the cases are performed and unilateral salpingectomy has been done in $61.0 \%$ of cases and $19.0 \%$ of patients are operated salpingectomy with contralateral tubectomy as thee patients are parous and have completed family. There are various means of treating ectopic pregnancy by laparoscopy. This includes laparoscopic linear salpingostomy, salpingotomy, salpingectomy and direct injection of cytotoxic agents ${ }^{14}$. There is reduced operating time, hospital stay, treatment cost, earlier return to activity, improved cosmetic result, less post-operative requirement of analgesia and morbidity in laparoscopy ${ }^{15}$. It is also preferable in cases of cornual or interstitial pregnancy. In a local study by Kulsum ${ }^{11} 91.0 \%$ cases, salpingectomy has been performed.

Most of the patients presented with ruptured or grossly damaged tube where conservative treatment is not possible. Only in $12.0 \%$ case linear salpingostomy has been done where there is unruptured ampullary tubal ectopic pregnancy. In this study salpingo-oophorectomy has not been done in any case; however, Zabin ${ }^{12}$ has shown that salpingo oophorectomy has been done in $19.0 \%$ cases. Therefore, the present declining rate of salpingooophorectomy may be due to the fact that conservation of ovary is getting more attention than removal ${ }^{11}$. There is no post-operative complication in the present study population.

The salpingostomy is performed with a small (less than $3 \mathrm{~cm}$ ), intact ampullary pregnancy ${ }^{16}$. A linear incision is made on the antimesenteric border directly over the site of ectopic pregnancy. After removing the products by fingers, scalpel handle or by suction, the incision line is kept open to be healed by secondary intention ${ }^{17}$. Haemostasis is achieved by electrocautery or laser. Recurrent ectopic is less, compared to salpingotomy. Both methods yield similar subsequent pregnancy rates of 40.0 to $90.0 \%$ cases. In unruptured tubal ectopic pregnancy and wishes to retain her fertility linear salpingotomy is the choice. This is of choice in isthmic pregnancy .A segmental resection with Primary microsurgical re-anastomosis has also been advocated but has the same result as linear salpingotomy and the latter is an easier and shorter procedure. This microsurgical reanastomosis after segmental resection of tube may be done when the affected tube is the only functioning tube and preservation of future fertility important in order to keep part of that tube ${ }^{18}$.

With fimbrial pregnancy, products of conception are often visible at the distal end of the tube, which may be plucked out. Milking the pregnancy through the abdominal ostium (transfimbrial extraction) has been advocated in the past but associated with persistent trophoblast and sometimes need for reexploration. However, the risk of recurrent ectopic pregnancy is twice as high as that with linear salpingotomy; therefore, this procedure is now obsolete $^{15}$. Removal of part or all of the affected tube is the usual procedure, if the patient has completed her family, if the tube appears to be grossly damaged or if ectopic pregnancy has recurred in a tube already treated conservatively. In the case of interstitial pregnancy the cornu of the uterus is excised as well. Practically in all cases the ovary can be conserved even though the surrounding blood clot makes it at first look beyond hope.

Unilateral salpingectomy reduces the chances of pregnancy by approximately one half ${ }^{5}$. If unilateral salpingo-oophorectomy is carried out, the chances of subsequent pregnancy are double because ovulation must then always take place from the ovary, which still has its oviduct. It follows that in a woman who is particularly anxious about future fertility it may be better to sacrifice than to save the ovary on an affected side. However, the developments of in vitro fertilization and embryo transfer and of microsurgery make conservation of 
the ovaries even more important ${ }^{9}$. Presently, salpingo-oophorectomy is never recommended unless the ovary itself is grossly diseased or damaged. If culdotomy has been performed for diagnositic purpose and the affected adnexum is found easily accessible salpingectomy or salpingooophorectomy can be carried out by the vaginal route. However this should be generally avoided because it does not permit proper assessment of the opposite tube and ovary, nor adequate peritoneal toilet. Before any operation is concluded, free blood and clots are removed from the peritoneal cavity. And before closing abdomen sometimes a drain tube is kept in situ. As soon as the haemoperitoneum is cleared, the patient usually follows a remarkably rapid recovery ${ }^{14}$.

The important feature of cornual pregnancy is that the sac is surrounded by myometrium and it can contain the pregnancy for a longer time than can the tube or ovary. Rupture of the horn therefore does not usually take place until $12^{\text {th }}$ to $20^{\text {th }}$ weeks but when it does, there is nearly always severe bleeding which make the condition extremely dangerous ${ }^{16}$. In some respects, cornual pregnancy resembles the interstitial type tubal pregnancy and they can be confused at operation. A distinguishing feature from interstitial pregnancy is the insertion of the round ligament, which is always lateral to the gestational sac in cornual pregnancy ${ }^{18}$. Excision of the rudimentary horn together with the pregnancy is the done usual. Sometimes hysterectomy is needed.

\section{Conclusion}

In conclusion most of the ectopic pregnancy is occurred in the site of ampulla of fallopian tube. Furthermore right side tube is the most common site of ectopic pregnancy than the left side. Most of the patients are presented with ruptured tubal pregnancy. In this study majority of the study population are surgically managed by unilateral salpingectomy followed by salpingectomy with contra lateral tubectomy. The number of cases in this study is comparatively small for inferences; therefore it should be reviewed by more detailed works with a large number of cases and nationwide.

\section{References}

1. Shrestha J, Saha R. Comparison of laparoscopy and laparotomy in the surgical management of ectopic pregnancy. $\mathrm{J}$ Coll Physicians Surg Pak. 2012;22(12):760-4
2. MacRae R, Olowu O, Rizzuto MI, Odejinmi F. Diagnosis and laparoscopic management of 11 consecutive cases of cornual ectopic pregnancy. Archives of gynecology and obstetrics. 2009;280(1):59.

3. Odejinmi F, Rizzuto I, Oliver R, Alalade A, Agarwal N, Olowu O. Beyond guidelines: effectiveness of a programme in achieving operative laparoscopy for all women requiring surgical management of ectopic pregnancy. Gynecologic and obstetric investigation. 2015;80(1):46-53.

4. Fujishita A, Khan KN, Kitajima M, Hiraki K, Miura S, Ishimaru T, Masuzaki H. Re-evaluation of the indication for and limitation of laparoscopic salpingotomy for tubal pregnancy. European Journal of Obstetrics \& Gynecology and Reproductive Biology. 2008;137(2):210-6.

5. Farahani L, Sinha A, Lloyd J, Islam M, Ross JA. Negative histology with surgically treated tubal ectopic pregnancies-A retrospective cohort study. European Journal of Obstetrics \& Gynecology and Reproductive Biology. 2017;213:98-101.

6. Ayaz A, Emam S, Farooq MU. Clinical course of ectopic pregnancy: A single-center experience. Journal of human reproductive sciences. 2013;6(1):70

7. Bora SA, Kirk E, Daemen A, Timmerman D, Bourne T. Is serum human chorionic gonadotrophin follow-up necessary after suspected spillage of trophoblast at the time of laparoscopic surgery for ectopic pregnancy?. Gynecologic and obstetric investigation. 2011;71(4):225-8

8. Kumar P, Malhotra N. Ectopic Pregnancy. In: Jeffcott's principles of Gynaecology, 7th edition. Chapter 9. New Delhi/London Arnold. 2008:142-160

9. VanMello NM, Mol F, Ankum WM, Mol BW, VanDer Veen $\mathrm{F}$, et al. Ectopic pregnancy: how the diagnostic and therapeutic management has changed. Fertility and sterility. 2012;98(5):1066-73

10. Hurrell A, Reeba O, Funlayo O. Recurrent ectopic pregnancy as a unique clinical sub group: a case control study. Springer Plus. 2016;5(1):265

11. Kulsum SU. Study on risk factors, clinical presentations and operative management of Ectopic pregnancy, IPGMR, Dhaka, 2002, [FCPS Dissertation]

12. Zabin F. Study on clinical presentations, management and operative findings of ectopic pregnancy. IPGMR Dhaka, 1998 [FCPS Dissertation].

13. Archibong E, I Sobanda A. Ectopic pregnancy. In Abudhabi, Saudia Arabia. Saudia Medical Journal, 2000;21(4):330-34

14. Chatterjee S, Dey S, Chowdhury RG, Ganguli D. Ectopic pregnancy in previously infertile women subsequent pregnancy outcome after laparoscopic management. Al Ameen J Med Sci. 2009;2(1):67-72

15. Yoon BS, Park H, Seong SJ, Park CT, Jun HS, Kim IH. Single-port versus conventional laparoscopic salpingectomy in tubal pregnancy: a comparison of surgical outcomes. European Journal of Obstetrics \& Gynecology and Reproductive Biology. 2011;159(1):190-3

16. Pokharel HP, Dahal P, Rai R, Budhathoki SS. Surgical emergencies in obstetrics and gynaecology in a tertiary care hospital. Journal of Nepal Medical Association. 2013;52(189):213-6

17. Hamura NN, Bolnga JW, Wangnapi R, Horne AW, Rogerson SJ, Unger HW. The impact of tubal ectopic pregnancy in Papua New Guinea-a retrospective case review. BMC pregnancy and childbirth. 2013;13(1):86

18. Spandana N, Togarikar SM, Polepaka D. A Retrospective Study of Ectopic Pregnancy in a Tertiary Care Hospital. Management 2016;4:19-04 